\title{
O design de produção enquanto design especulativo decolonial: tipografia vernacular e design informal em Bacurau
}

\author{
Production design as decolonial speculative design: vernacular typography \\ and non-formal design in Bacurau
}

Laura Linck Maciel, Eduardo A B M Souza

tipografia vernacular, design de produção, design especulativo, decolonialidade

\begin{abstract}
A partir da relação entre design especulativo e design de produção para a construção de cenários e mundos narrativos, compreendemos as expressões tipográficas do filme pernambucano Bacurau como artefatos gráficos especulativos decoloniais. Para argumentar isso, analisamos alguns desses artefatos apresentados no filme a partir do esquema de metodologia visual crítica, elaborando sobre as modalidades tecnológica, composicional e social do setor da imagem em si. Assim, apontamos que a expressão tipográfica do povo de Bacurau é caracterizada pela tipografia vernacular e pelo design informal, enquanto a dos estrangeiros é caracterizada por elementos das interfaces digitais. Portanto, os artefatos gráficos reiteram o aspecto decolonial que permeia os demais aspectos do filme.
\end{abstract}

vernacular typography, production design, speculative design, decoloniality

By discussing speculative design and production design practices to build scenarios and narrative worlds, we understood typographic expressions in the movie Bacurau as decolonial speculative graphic designs. In order to argue this, we analyzed some of the designs presented by the movie based on a critical visual methodology framework, discussing technological, compositional and social modalities in the site of image itself. Thus, we point out that Bacurau people's typographic expressions is characterized by vernacular typography and non-formal design, while foreigners' are characterized by digital interface elements. Therefore, typographic designs in the movie reiterate decolonial aspects imbued in it.

\section{Introdução}

No design, a construção de cenários é abordada sobretudo pelo design crítico e especulativo (Dunne \& Raby, 2013) e pelo Design Fiction (Coulton et al, 2017): essas abordagens experimentam com a criação de artefatos ficcionais que podem servir de pontos de entrada para um mundo narrativo e, a partir disso, explorar a coesão desse mundo. Entretanto, segundo Martins \& Oliveira (2015), elas não têm explorado cenários alternativos como uma maneira de discutir privilégios raciais, de classe, de gênero e questões de decolonialidade.

Essa capacidade de criar mundos narrativos também é explorada pelo cinema, para a qual a dimensão visual é essencial (Machado, 2009) e na qual o design de produção desempenha um papel crescente, a ponto de englobar toda a visualidade dos filmes (Couto, 2004). Logo, o design de produção de uma distopia cinematográfica pode ser considerado uma prática de

Anais do $10^{\circ} \mathrm{CIDI}$ e $10^{\circ} \mathrm{CONGIC}$

Kelli C.A.S. Smythe, Rafael de Castro Andrade (orgs.)

Sociedade Brasileira de Design da Informação - SBDI

Curitiba | Brasil | 2021
Proceedings of the $10^{\text {th }} \mathrm{CIDI}$ and $10^{\text {th }}$ CONGIC

Kelli C.A.S. Smythe, Rafael de Castro Andrade (orgs.)

Sociedade Brasileira de Design da Informação - SBDI Curitiba | Brazil | 2021 
design especulativo, pois cria artefatos para um mundo ficcional. Nesse sentido, analisamos os artefatos gráficos na obra pernambucana Bacurau (2019), de Kleber Mendonça Filho e Juliano Dornelles. Assim, argumentamos que, por meio da tipografia, o design de produção reitera o posicionamento decolonial do filme.

\section{Referencial teórico}

O design crítico e especulativo (SCD) despontou conforme apresentado por Dunne (2005) e difundiu-se com Dunne \& Raby (2013), defendendo o design como uma atividade que superaria as limitações de necessidades do mercado. Entretanto, segundo Laranjo (2020), a prática se desvencilhou do compromisso e responsabilidade da prática crítica e tornou-se perfeito para ser usado como um capricho. Várias discussões concordam que essa prática se desenvolveu de maneira elitista e excludente (Bardzell \& Bardzell, 2013; Tonkinwise, 2014). Assim, continua Laranjo (2020), um design que não critica e não especula sobre o futuro que queremos construir, não deveria ser considerado design. Por isso, alguns praticantes buscaram resgatar o crítico do design crítico e especulativo (Martins \& Oliveira, 2015).

O cinema é uma forma de expressão propícia para a construção de cenários especulativos, já que exerce efeito de ilusionismo desde seus primeiros usos no teatro de Vaudeville (Cook, 2016). Devido a essa capacidade, Bentes (2007) aponta que o cinema muitas vezes assume papéis críticos a partir de questões reais, com o dever ético de não cair em estereótipos. Sobre a representação do sertão, a autora aborda questões tanto éticas quanto estéticas. Nesse sentido, Bacurau (2019) pode ser compreendido como uma resposta, pois, em diversas instâncias, expressa valores decoloniais (Gomes \& Trovão, 2020), embora não tenha pretensão realista ou documental como o Cinema Novo analisado por Bentes (2007).

Considerando a perspectiva de Spyer (2020), caracterizamos o filme como uma ficção especulativa distópica decolonial, que busca uma representação alternativa do sertão; aqui, o sertão, concatena tecnologia, sagacidade, pertencimento e força. Ou seja, Bacurau se apodera de elementos visuais a fim de se desvincular de imagens já fixadas no repertório visual do público. Para isso, a equipe de design de produção busca estabelecer um senso de autenticidade com nuances entre a fidelidade à realidade e a criação de imaginário, utilizando ferramentas investigativas acerca do universo narrativo (LoBrutto, 2002). Embora pouco discutida, a tipografia assume um papel importante na construção desses mundos fictícios, pois a expressão da linguagem verbal corresponde à "imagem da sociedade dentro de sua evolução dinâmica" (Mandel, 2006 p. 18).

Esse aspecto da linguagem gráfica verbal fica evidente na tipografia vernacular. Finizola (2015) atribui o valor do vernacular ao reconhecimento construído pela tradição, conceituada pelo uso cotidiano dos artefatos gráficos em determinadas regiões. Assim, a autora atribui o termo "design informal" a essas práticas passadas por gerações, como o ofício dos pintores de letras. Esses registros gráficos vernaculares encontrados nas paisagens urbanas expressam as vozes da periferia, hábitos e costumes do povo. Geralmente, são desenvolvidos por meio de 
processos artesanais, caracterizando-se como "instrumento de comunicação alternativo" (Finizola, 2015). Analisamos algumas das instâncias tipográficas para traçar a oposição entre a tipografia vernacular presente nas expressões bacurauenses e a tipografia moderna dos colonizadores. Para isso, utilizamos os princípios da metodologia visual crítica delineada por Rose (2017) (Figura 1). Nossa discussão enfatiza a instância da imagem em si, contemplando suas três modalidades.

Figura 1: Esquema analítico proposto por Rose. Essa discussão enfatizará o setor da imagem em si. Fonte: Rose (2017)

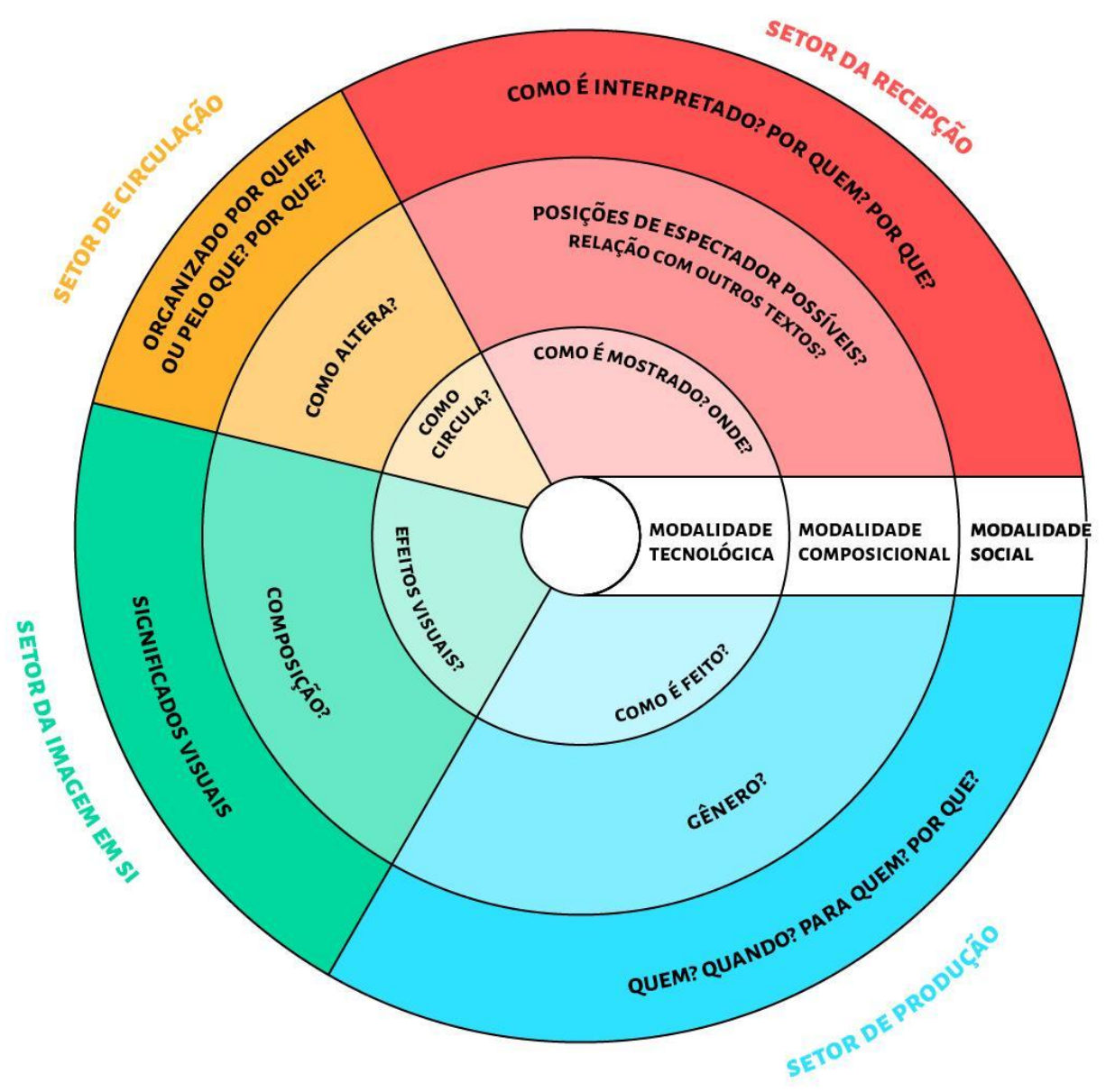

\section{Discussão}

Em entrevista para a Folha (2020), o diretor Kleber Mendonça Filho discute a consciência que o filme deve ter em relação a questões já marcadas por estereótipos. Assim, devemos tomar cuidado com determinadas imagens e conceitos. Isso concorda com os objetivos do guia rápido para realizar um projeto de design especulativo não-colonialista proposto por Oliveira \& Martins (2016). Ou seja, é necessário que o design especulativo e os processos de construção de futuros distópicos considerem os atravessamentos políticos e as assimetrias de poder em suas representações. 
Figura 2: Placa de Bacurau. Fonte: Bacurau (2019)

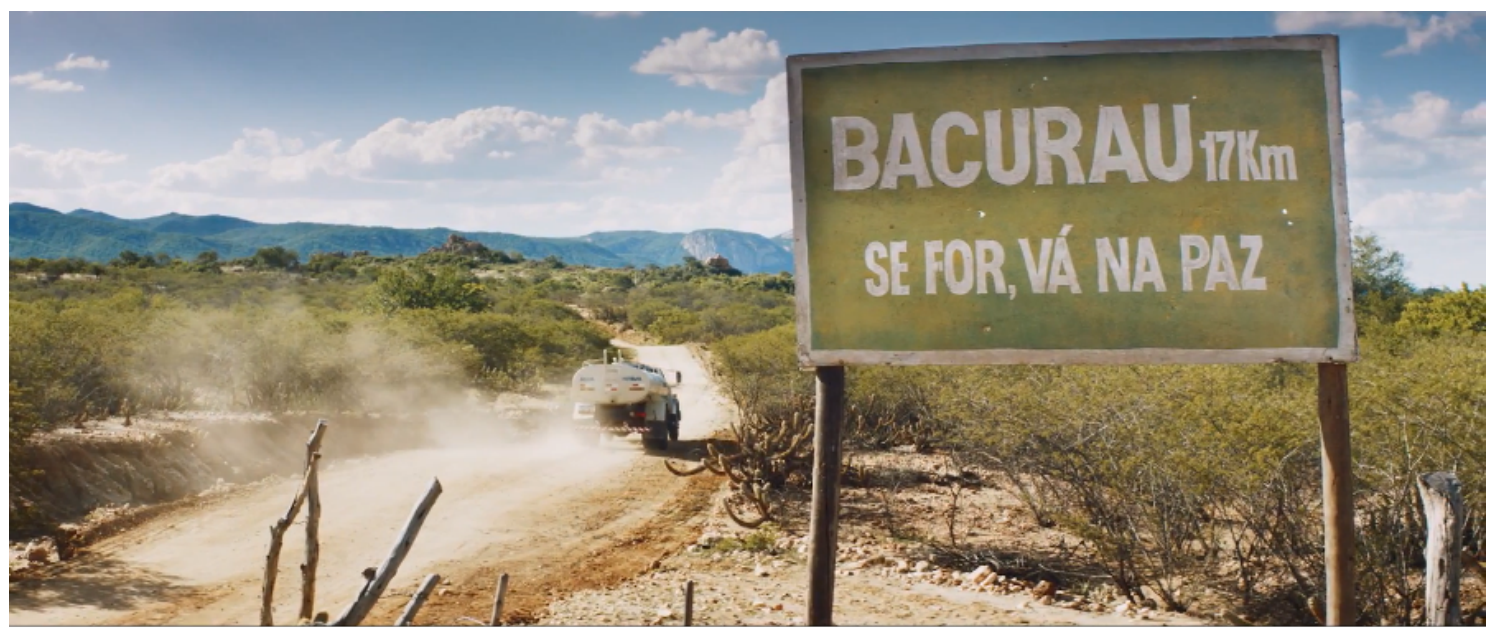

Figura 3: Exemplo do padrão de placa indicativa de distância no Brasil. Fonte: Site do Departamento de Estradas de Rodagem de Alagoas

$$
\begin{array}{ll}
\text { GUAÍBA } & 100 \mathrm{~km} \\
\text { PELOTAS } & 330 \mathrm{~km} \\
\text { URUGUAIANA } & 700 \mathrm{~km} \\
\text { LIVRAMENTO } & 570 \mathrm{~km}
\end{array}
$$

A paisagem de Bacurau reflete as necessidades de comunicação dos moradores da vila. Essa comunicação se dá por meio de tipografias vernaculares e design informal, conforme caracterizados por Finizola (2015). Na Figura 2, temos uma das primeiras ocorrências tipográficas no universo narrativo do filme (diegética) e, definitivamente, a mais famosa. A respeito da modalidade tecnológica, o acabamento dos desenhos tipográficos apresenta certa irregularidade que indicam que foram feitos à mão, de maneira similar aos letristas estudados por Finizola (2015). Isso também parece ser indicado pela composição, dado que a distribuição das informações desobedece aos critérios das normas de placas (Figura 3). Por fim, a modalidade social fica explícita pelo caráter de resistência política que assumiu na sociedade brasileira, demonstrando claramente como esses artefatos que compõem o universo narrativo são capazes de transbordar para a realidade (Figuras 4, 5 e 6). 
Figuras 4, 5 e 6: Produtos decorativos feitos com base na placa de Bacurau, demonstrando que se tornou um símbolo de posicionamento político. Fonte: Elo 7, Mercado Livre e Loja El Cabritón

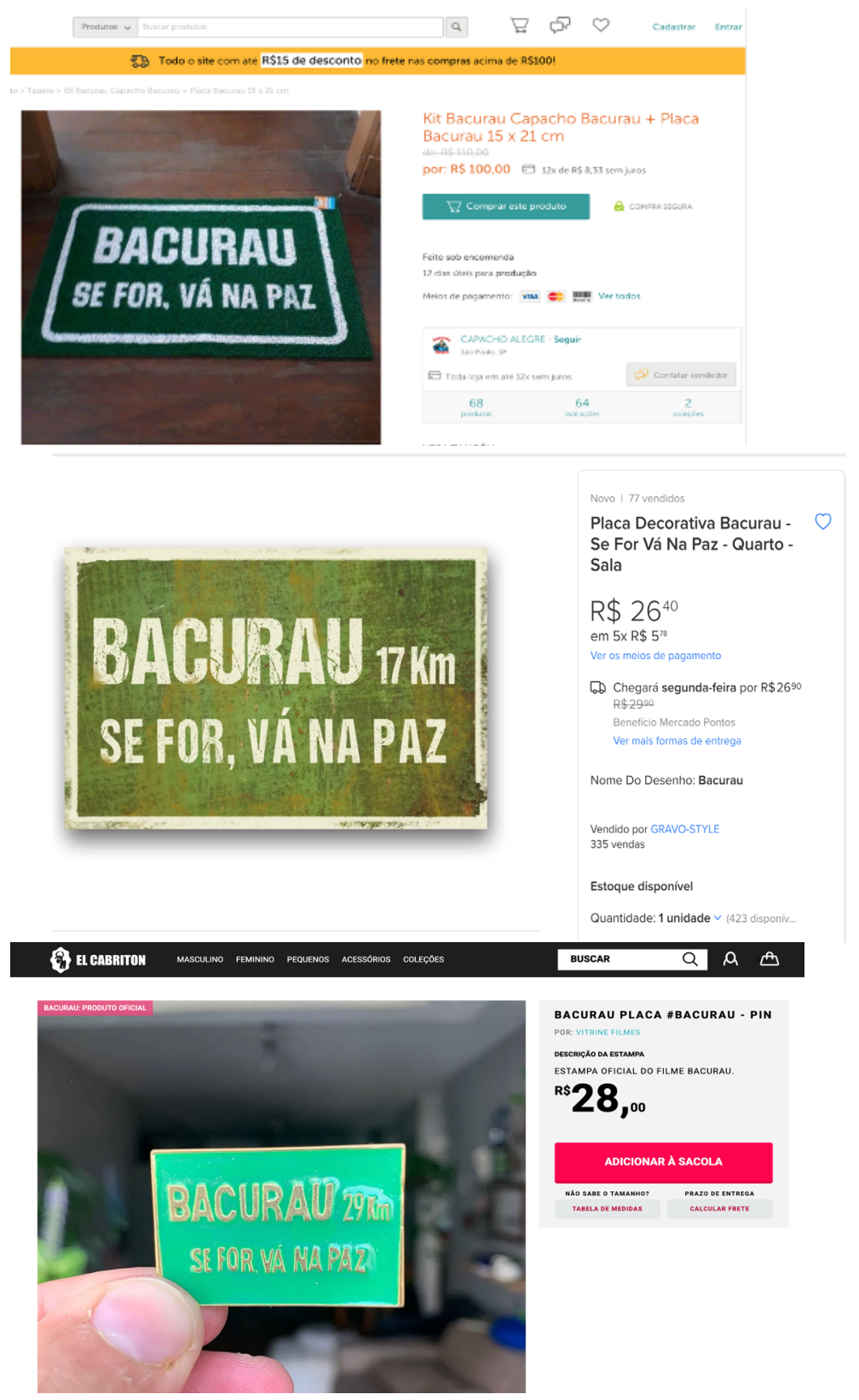

Na Figura 7, os avisos escolares são caracterizados pela familiaridade. A modalidade social fica clara quando observamos que a organização informacional e o uso das tipografias apresentam recursos comumente utilizados em artefatos gráficos feitos por "não-profissionais" de design gráfico, caracterizando o que Finizola (2015) define como design informal. Isso pode ser constatado pelas modalidades tecnológica e composicional, já que os avisos denotam o uso de softwares de processamento de texto como o Microsoft Word para sua composição. A distorção horizontal da tipografia no aviso "FERAS NO VESTIBULAR" é o exemplo mais claro de algo que é considerado um “crime tipográfico" (Lupton, 2013), mas que é um recurso motivado pela necessidade de resolver um problema; para Finizola (2015), a criação de artefatos vernaculares é intuitivo e, assim, ignora as regras do design formal. 
Figura 7: Quadro de avisos da escola de Bacurau. Fonte: Bacurau (2019)

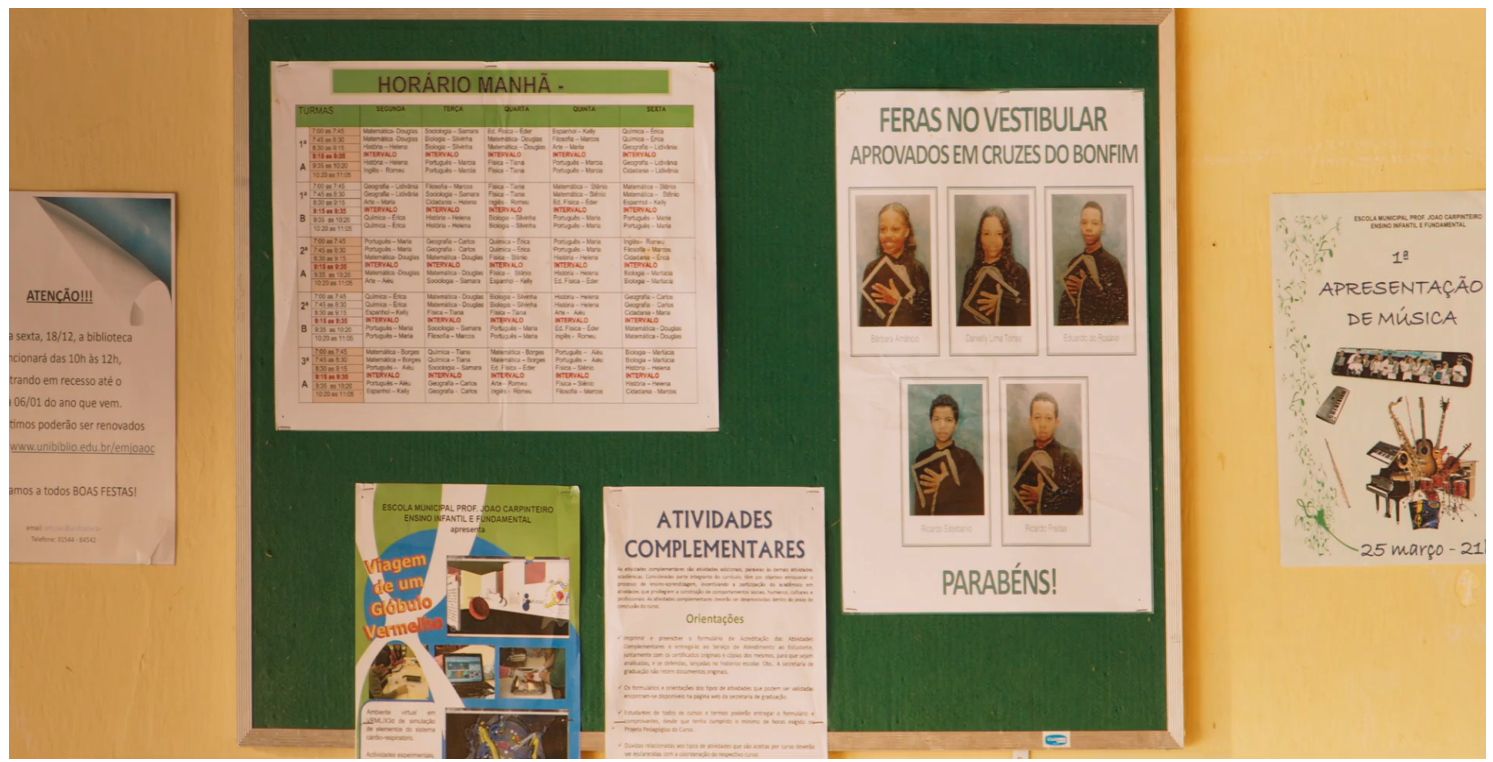

Ao comparar essas expressões tipográficas produzidas pelos bacurauenses com os artefatos gráficos dos estrangeiros e do prefeito da cidade, a mudança tanto no desenho tipográfico quanto na organização informacional dos artefatos é notória. A Figura 8 ilustra a interface do drone dos estrangeiros. O artefato gráfico já não é mais analógico, mas digital, uma mudança abrupta na modalidade tecnológica. Acerca da composição, a tipografia geométrica sem serifa utilizada juntamente com caixas, ícones e outros elementos esquemáticos (gráficos, diagramas, linhas) remetem a um referencial "futurista", como na já clássica interface de Minority Report (2002) (Figura 9). Assim, a modalidade social caracterizada por esse futurismo é inteiramente desconstruída pelo bacurauense: "Ontem eu vi um drone. Parecia um disco voador de filme antigo, mas era um drone".

Figura 8: Interface do drone utilizado pelos estrangeiros contra o povo de Bacurau. Fonte: Bacurau (2019)

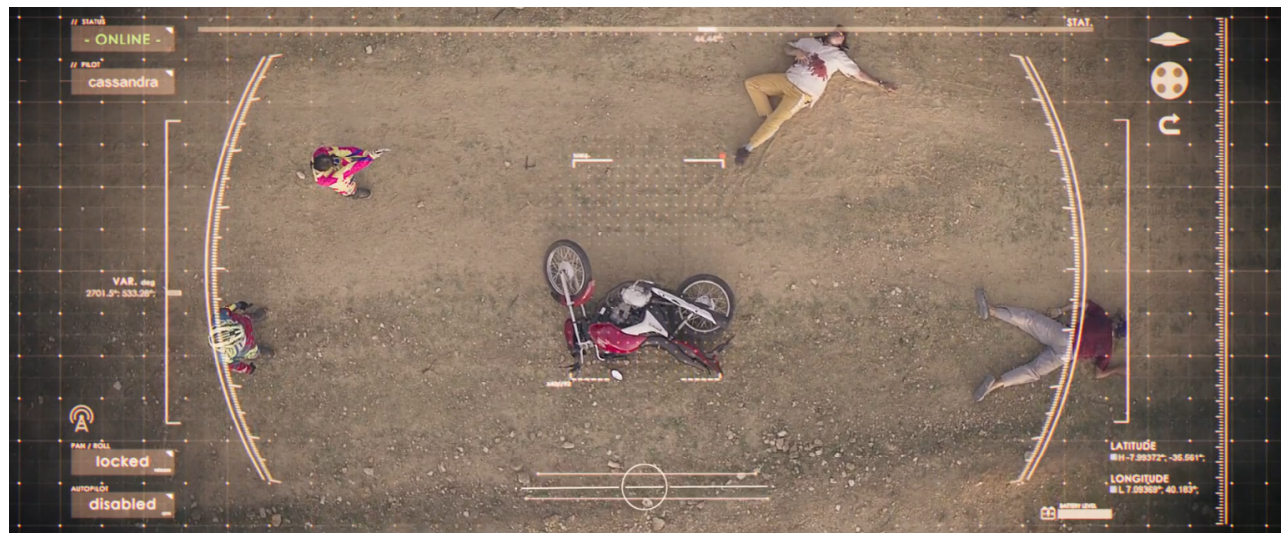


Figura 9: Interface de Minority Report (2002) que tornou-se um paradigma de "futurismo". Fonte: Minority Report (2002)

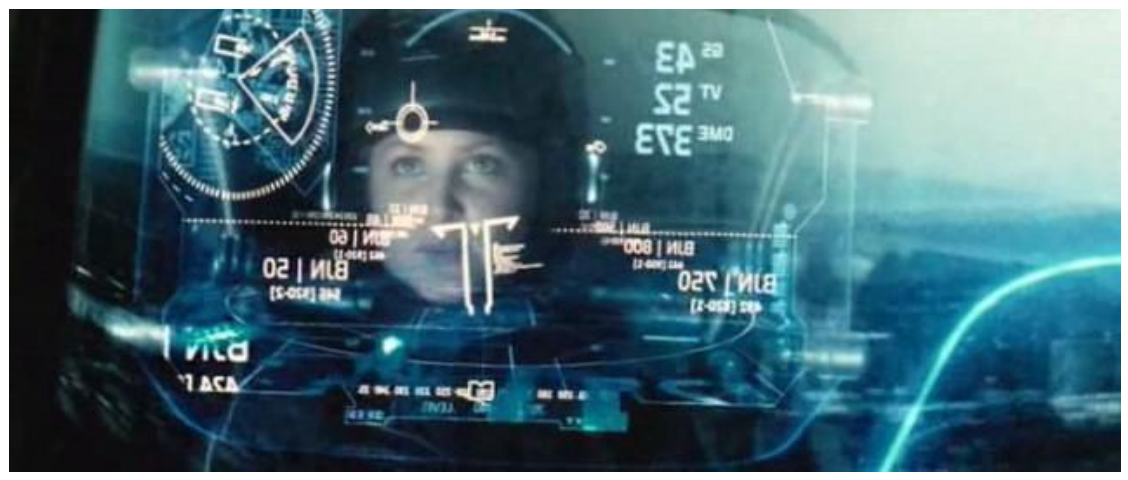

\section{Considerações finais}

A partir de críticas ao SCD e ao design fiction, defendemos que o cinema é frutífero para a construção de cenários. Então, identificamos Bacurau como uma narrativa distópica decolonial e buscamos analisar os artefatos gráficos utilizados pelo design de produção caracterizar a resistência do povo. De acordo com o esquema metodológico de Rose (2017), analisamos o setor da imagem em si. Assim, demonstramos que há contraste entre as tipografias utilizadas pelos habitantes da cidade e as observadas nos artefatos dos estrangeiros em todas as modalidades. Com isso, argumentamos que a resistência dos bacurauenses repercute na tipografia vernacular, que busca afirmar a identidade do povo, articulado ao caráter decolonial que permeia o filme. Acreditamos que estudos futuros devem empreender esforços similares para articular os artefatos de design com seus contextos e discursos. Da perspectiva do design especulativo, isso significa potencializar a dimensão política da construção de cenários para o bem comum. De outro lado, isso se mostrou altamente profícuo no design de produção do cinema brasileiro, que deve ser encorajado e reforçado.

\section{Referências}

Bardzell, J., \& Bardzell, S. (2013). What is "critical" about critical design? 3297. https://doi.org/10.1145/2470654.2466451

Bentes, I. (n.d.). Sertões e favelas no cinema brasileiro contemporâneo: Estética e cosmética da fome. 14.

Cook, D. A. (2016). A history of narrative film (Fifth edition). W.W. Norton \& Company.

Coulton, P., Lindley, J., Sturdee, M., \& Stead, M. (2017). Design Fiction as World Building. In Proceedings of Research through Design Conference 2017. Lancaster University. https://eprints.lancs.ac.uk/id/eprint/83974/

Couto, C. S. C. (2004). O Design do filme [Dissertação de mestrado]. Universidade Federal de Minas Gerais.

Dunne, A., \& Raby, F. (2013). Speculative everything: Design, fiction, and social dreaming. The MIT Press. 
Finizola, F. (2015). A tradição do Letreiramento Popular em Pernambuco-Uma investigação acerca de suas origens, forma e prática | The tradition of vernacular lettering in Pernambuco-An investigation about its origins, forms and practice [Tese de doutorado, Universidade Federal de Pernambuco]. http://rgdoi.net/10.13140/RG.2.1.5010.8562

Gomes, A. R., \& Trovão, F. V.-B. (2020). O voo do Bacurau: Cinema, necropolítica e [contra]violência. Fênix - Revista de História e Estudos Culturais, 17(17), 231-261. https://doi.org/10.35355/revistafenix.v17i17.951

Laranjo, F. (2020, November 17). Francisco Laranjo: We don't need Speculative Design education, just better design education [Site]. https://speculativeedu.eu/interview-franciscolaranjo/

Lupton, E. (2013). Pensar com tipos: Guia para designers, escritores, editores e estudantes. $\left(2^{a}\right.$ Edição revista e ampliada). Cosac Naify.

Mandel, L. (2006). Escritas, espelho dos homens e das sociedades. Rosari.

Martins, L. P. de O., \& Oliveira, P. J. S. V. de. (2015). Futuristic Gizmos, Conservative Ideals: On Speculative Anachronistic Deisgn. In F. Laranjo (Ed.), Critical, Uncritical, Post-critical. Modes of Criticism.

Oliveira, P. J. S. V. de, \& Martins, L. P. de O. (2016). Como fazer um projeto de Design Especulativo Não-Colonialista: Um Guia Rápido [Blog]. A-Pare.De. https://www.academia.edu/31049931/Como_fazer_um_projeto_de_Design_Especulativo_N \%C3\%A3o-Colonialista_Um_Guia_R\%C3\%A1pido

Spyer, T. (2020). Distopias à brasileira: 'Bacurau' e Divino 'Amor.' Revista Epistemologias Do Sul, 3(1), 92-109.

Tonkinwise, C. (2014). How We Intend to Future: Review of Anthony Dunne and Fiona Raby, Speculative Everything: Design, Fiction, and Social Dreaming. Design Philosophy Papers, 12(2), 169-187. https://doi.org/10.2752/144871314X14159818597676

\section{Sobre os autores}

Laura Linck Maciel; IFPE; Recife, Recife, Pernambuco, Brasil; linck.lauram@gmail.com Eduardo A B M Souza; Mestre; IFPE/UFPE; Recife, Pernambuco, Brasil; eduardosouza@recife.ifpe.edu.br 